\title{
Coversheet
}

This is the accepted manuscript (post-print version) of the article.

Contentwise, the post-print version is identical to the final published version, but there may be differences in typography and layout.

How to cite this publication

Please cite the final published version:

Thylstrup, B., Clausen, T., \& Hesse, M. (2015). Cardiovascular disease among people with drug use disorders. International Journal of Public Health, 60 (6), 659-668. DOI: 10.1007/s00038-015-0698-3

\section{Publication metadata}

Title:

Author(s):

Journal:

DOI/Link:

Document version:
Cardiovascular disease among people with drug use disorders in Denmark [Birgitte Thylstrup, Thomas Clausen, Morten Hesse International Journal of Public Health 10.1007/s00038-015-0698-3 Accepted manuscript (post-print)

\section{General Rights}

Copyright and moral rights for the publications made accessible in the public portal are retained by the authors and/or other copyright owners and it is a condition of accessing publications that users recognize and abide by the legal requirements associated with these rights.

- Users may download and print one copy of any publication from the public portal for the purpose of private study or research.

- You may not further distribute the material or use it for any profit-making activity or commercial gain

- You may freely distribute the URL identifying the publication in the public portal

If you believe that this document breaches copyright please contact us providing details, and we will remove access to the work immediately and investigate your claim. 
Cardiovascular disease among people with drug use disorders in Denmark

Birgitte Thylstrup, Associate Professor ${ }^{1}$

Thomas Clausen, Professor ${ }^{2}$

Morten Hesse, Associate Professor ${ }^{1}$

${ }^{1}$ Centre for Alcohol and Drug Research, Aarhus University, Denmark

${ }^{2}$ Intitute of Clinical Medicine, University of Oslo, Norway 


\begin{abstract}
Aims

The aim of this study was to present prevalence and incidence of cardiovascular disease (CVD) in a consecutive national cohort of patients seeking outpatient treatment for drug use disorders (DUD). Additionally risk factors for developing CVDs were investigated.
\end{abstract}

\title{
Participants
}

A total of 18,275 patients who sought outpatient treatment for illicit DUD in Denmark during a 6year period were linked with national registers of hospital contacts and causes of death. Prevalence was compared with a reference population. Cox proportional hazard regression was used to predict incidence of new CVD.

\section{Results}

In all, 828 individuals (4.53\%) had been diagnosed with a CVD within a ten-year time span leading up to admission to DUD treatment. Among the remaining patients; 17,262 were traced through health and cause-of-death registers, and among the 17,262 patients 1,529 new incident cases of CVD were observed during a mean follow-up time of 6.6 years (1237 per 100,000 person years). Incident CVD was independently associated with use of prescription methadone use of benzodiazepines, referrals to methadone treatment, intravenous drug use, and higher age. Use of amphetamine was negatively associated with risk of CVD within this cohort.

\section{Conclusions}

Patients prescribed methadone and using drugs intravenously are at elevated risk for cardiovascular disease and should be monitored for heart problems. 


\section{Introduction}

Cardiovascular disease (CVD) constitutes a significant and increasing burden on healthcare systems and is a significant cause of premature death globally (Danaei, Finucane, et al., 2011; Danaei, Stevens, et al., 2011; Farzadfar et al., 2011). People with drug use disorders (DUD) are at risk of premature death from a range of causes (Degenhardt \& Hall, 2012; Nordstrom, Yokoi-Shelton, \& Zosel, 2013; Nyhlén, Fridell, Hesse, \& P., 2011), but little is known about the burden of CVD in patients with DUD.

Use of illicit drugs may lead to CVD in a number of ways: although drug use is a diverse phenomenon, and people with DUD form a heterogeneous group, particular risk factors exist. Injection use may lead to venous disease (Pieper, Kirsner, Templin, \& Birk, 2007), and a substantial proportion of injection drug users experience thrombosis, septicaemia or endocarditis (Salmon et al., 2009). Further, high doses of methadone may cause QT interval prolongation (Kao et al., 2013; Roy et al., 2012), and high doses of cocaine and amphetamine are known to be associated with acute vascular events (De Giorgi et al., 2012; Figueredo, 2011). Additionally, case reports have indicated that cannabis use may be associated with acute risk of myocardial infarction (Desbois \& Cacoub, 2013).

Since CVD is a leading cause of mortality and lowered quality of life in general (McKenna, Michaud, Murray, \& Marks, 2005), it is important to identify groups at high risk for CVD, in order to prevent and adequately treat new cases. Little is currently known about the prevalence and incidence of CVD in DUD populations, and clinicians would benefit from further nuanced knowledge and thereby being better equipped for both the prevention of and treatment of CVD in their diverse patient populations.

The aims of this study were to assess the prevalence of CVD in a Danish national cohort of people who had sought treatment for a drug use disorder during the years from 2001 to 2007, and new incidences of CVD during follow-up until the end of 2011. Predictors of new incidence CVD in this treatment seeking DUD population were investigated using competing risks regression.

\section{Materials and Methods}

\subsection{Setting}


The setting was all Danish public outpatient substance abuse treatment centres during the years 2001-2007. All patients who sought treatment in any of these centres aged between 18 and 75 years were included in the study. All treatment in these institutions is free of charge, and the Danish Drug Abuse Treatment Register (DATR) was created to monitor patterns of illicit drug use and supervise treatment of drug-related problems in Denmark, and contains information on all individuals treated for drug-related problems at institutions receiving public funding.

\subsection{Participants}

This study included 18,275 patients over the age of 17 who were admitted for public outpatient treatment for DUD between January $1^{\text {st }} 2000$ and December $31^{\text {st }}$ 2006. All admissions and the date of patient's first admission for treatment during this period were included.

\subsection{Registers}

Data were retrieved from six national registers and were stored at a server in Statistics Denmark.

The Danish Substance Abuse Treatment Register (DSATR) includes data on drugs used before seeking treatment. The DSATR contains dummy codes for each drug, including illicit and prescribed methadone, benzodiazepines, heroin, buprenorphine, other opioids, cannabis, amphetamine, cocaine, alcohol, MDMA, LSD, and solvents. When admitting patients, staff members have to ask if the substance has been used during the past year. Additionally, the register includes basic demographic characteristics, such as level of education, source of income, civil status and number of children, and information about previous treatment history. Patients are identified by a unique identification number that allows identification of patients in other public registers. A total of $99.82 \%$ of entries in the database could be matched with other registers and could be included in the study. The remaining $0.18 \%$ may have had invalid ID-numbers and were therefore excluded from the study. For this study, illicit methadone and prescribed methadone were entered as separate variables, and other opioid agonists and heroin were combined as one category. Ecstasy, LSD and solvents were excluded from the analyses, due to the low frequencies of these drugs $($ all $<10 \%)$. Assessing the coverage of the DSATR can only be done by proxy, as we have no independent source of knowledge about patients at each treatment centre. The best data we had available was an independent register, DANRIS (Pedersen, Hesse, \& Bloomfield, 2011), of persons who received residential treatment for DUD during the same period with a total of 6,355 individuals. Since most 
individuals who enter residential treatment are referred through the outpatient clinics, we would expect that most patients in the residential register were also registered in the DSATR, although a smaller proportion of patients in residential care are paid for by family or employers, and would therefore not be registered in the DSATR. In fact, $84.28 \%$ of the 6,355 individuals in the residential treatment register were also in the DSATR, indicating that there is an acceptable amount of coverage.

The National Patient Registry covers all public hospital contacts in Denmark, including inpatient, day hospital and emergency units, and gives discharge diagnoses, using the ICD-10 codes. All treatment in Danish public hospitals is free for patients.

The Cause of Death Register covers all deaths in Denmark, and was used to establish the mortality rate, time and cause of death, using the ICD-10 codes.

Additional registers included the National Criminal Justice register, the Psychiatric Demographic Register, and basic demographic registers to assess legal, psychiatric and immigration status and employment status.

\subsection{Outcome variables}

The study focused on two outcome variables:

1. Prevalence of CVD was defined as an inpatient episode where the primary ICD-10 diagnosis for the episode was a disease of the circulatory system (I00-I99), and the episode was an inpatient episode. Additionally, CVD was considered prevalent if the patients were given a diagnosis of heart failure (I11.0, I13.0, I13.2, I50) or atrial fibrillation and flutter (I48) during outpatient hospital contacts, including general outpatient contacts and emergency room admissions. All incidents within the 3650 days leading up to admission for DUD were coded.

2. New incidence after drug use treatment was defined, using the same diagnoses. In addition, patients were considered incident if cause of death was coded as a disease of the circulatory system (I0-I99). 


\subsection{Analyses}

Prevalence was estimated in five-year intervals of age by gender. Incidence was estimated among patients who had never been diagnosed with CVD at first observed admission to treatment for DUD. Univariate odds ratios are reported for differences between patients with a history of CVD and other variables.

Competing risks regression was used to assess links between patient variables and CVD incidence (Haller, Schmidt, \& Ulm, 2013). The competing risk in this context was dying from a non-CVD related cause. Competing-risks regression posits a model for the subhazard function of a causespecific event of primary interest that occurs in a situation when other events can occur that prevent the primary event from happening. In this case, if patients die from a cause that is unrelated to CVD, they are no longer at risk for CVD, yet they cannot be considered censored either. In the presence of such competing failure events, a standard Cox proportional hazards regression can produce incidence-rate curves that are not appropriate, and the effects of covariates on these curves cannot be quantified. Competing-risks regression provides an alternative model that can produce incidence curves that represent the observed data, and for which describing covariate effects is straightforward.

The maximum likelihood approach to competing risks regression was conducted according to the method of Fine and Gray (1999).

The predictor variables were age, gender, the presence or absence of various types of drugs (use of licit or illicit methadone, other opioid agonists, cannabis, cocaine, amphetamines, benzodiazepines, alcohol), and injection use. For injection use, the following codes were used: (1) Never injected, (2) Ever injected, (3) Not reported.

In order to control for overall functioning which also indicates severity of drug use problems, the following predictor variables were included: working or studying in the calendar year when patients were admitted to treatment for DUD, whether the patients had been charged with an offence during the past 365 days leading up to treatment for DUD, and whether the patients had received any care at a psychiatric facility during the last 365 days before entering treatment for DUD. In a preliminary analysis, we also controlled for number of different drugs used, however, this variable had to be dropped due to significant co-linearity with the remaining variables. 
We estimated the variance inflation factor for the remaining variables, a quantifier of the severity of multicollinearity. Traditional cut-offs have been shown to be excessively restrictive (O'Brien, 2007), so we chose a cut-off value of 10 or higher for this study to combine variables.

Finally, logistic regression was used to assess associations between significant predictors from the competing risks model and the five most common types of CVD.

All analyses were carried out using Stata 13 for Windows.

\section{Results}

\section{Sample description}

The mean age at the time the patients entered treatment for DUD was 31.4 years (SD = 9.6); 13,546 (76.0\%) of the patients were male. Of all patients, $46.4 \%$ reported using opioids prior to entering treatment, 50.6\% reported cannabis, $17.8 \%$ reported benzodiazepine use, $19.2 \%$ reported amphetamine use, $19.7 \%$ reported cocaine use, and 24.2\% reported alcohol use. Of the sample, 7.3\% reported abstinence at intake. The mean number of drugs reported per respondent was 2.1 $(\mathrm{SD}=1.7)$.

Of the sample, $36.0 \%$ reported never injecting drugs, $12.2 \%$ reported injecting, but never sharing injection equipment, $16.4 \%$ reported sharing injecting equipment, and $35.4 \%$ did not answer the question. For particular drugs, $36.7 \%$ of heroin users reported injecting the drug, as did $0.2 \%$ of those reporting prescription methadone use, $8.9 \%$ of those reporting illicit methadone use, $2.6 \%$ of those reporting other opioid use $5.6 \%$ of amphetamine users, $15.3 \%$ of cocaine users, and $1.6 \%$ of those reporting benzodiazepine use.

\section{Differences between patients with and without CVD}

Generally, the patients with CVD had a more severe history of drug use and social maladjustment. Patients with CVD were more often prescribed methadone, used other opioids and benzodiazepines and less often cocaine, amphetamine, cannabis and alcohol. The patients also injected more often, had a previous treatment history, were more likely to be referred to methadone treatment, and were 
more likely to have a criminal and psychiatric history (Table 1). Also, patients with CVD were older and more often women.

\section{Prevalence}

The prevalence of CVD at treatment entry was 4.53\% (828 patients). Descriptive statistics are given in table 2 for patients with and without CVD. For comparison, data from a study of a general population sample from Denmark based on 2009 figures are included (Koch, Davidsen, \& Juel, 2011). The most remarkable differences for both genders are in the age bracket from 35 to 44 years of age, when the proportion with CVD is more than doubled among patients with DUD compared to the general population estimates.

\section{Incidence}

Due to the exclusion of a small number of patients who had been diagnosed with CVD before 10 years prior to entering treatment for DUD and missing data on work status, 17,262 patients could be included (98.93\% of patients at risk). The mean follow-up time period per patient was 6.6 years for the 17,262 patients who did not have CVD at entry into treatment (range: 0-11 years).

After admission to substance abuse treatment, 1,529 patients were diagnosed with a CVD, either in a hospital or as the cause of death (8.86\% of all patients at risk). A total of $1,847(11.70 \%)$ of the atrisk patients died during follow-up, i.e. before December $1^{\text {st }} 2011$, and 86 died of CVD.

The variance inflation factor for the predictors ranged from 1.02 to 1.47 , indicating minimal multicollinearity, far below recommended thresholds (O'Brien, 2007).

Within-group predictors of incidence are summarized in Table 3. Significant predictors included prescription use of methadone prior to treatment entry, benzodiazepine use, a history of injection use, missing data on injection use, being referred for methadone substitution treatment, higher age at intake, and criminal history. 
Figure 1 shows the cumulative index function by methadone use (left-hand panel) and by selfreported injection drug use (right-hand panel). As can be seen, both factors are associated with increased risk of new-incidence CVD.

\section{Types of CVD}

Table 4 shows the types of incident CVD observed in the cohort covering the entire observation period. The most common types of CVD were diseases of veins, lymphatic vessels and lymph nodes, followed by cerebrovascular disease, ischemic heart disease and diseases of arteries, arterioles and capillaries. Among the causes of death, the most common were ischemic heart disease and cerebrovascular disease.

Additionally, we tested the associations between the most common diseases and the significant predictors from the competing risks analysis. All of the covariates for overall CVD were associated with diseases of veins, lymphatic vessels and lymph nodes. None of the predictors for overall CVD were associated with ischemic heart disease. Reporting injection use, not answering the question about injection use, and having used prescription methadone prior to entering treatment for substance use disorders were all associated with diseases of the arteries.

\section{Discussion}

The findings show a high prevalence of CVD at a relatively young age among patients with DUD at entry to DUD treatment compared to published data from the general population in Denmark. The statistically significant risk factors for CVD were having used prescribed methadone or benzodiazepines prior to entering treatment, reporting lifetime injection drug use, being referred for methadone maintenance, and criminal history.

Incidence of CVDs for the group who entered DUD treatment was 1,529 including 86 cases of deaths with CVD causes, corresponding to 1,360 new incidence cases per 100,000 person years. This incidence is higher than the incidence of 1,004 per 100,000 men and 661 per 100,000 women reported for the age span of 45-54 years in the general population in Denmark (Koch et al., 2011), despite the fact that the cohort in this study was aged 38 years on average at the end of follow-up. 
In terms of the specific mechanisms linking drugs of abuse, routes of administration and specific conditions, large-scale studies such as this may not provide us with the detailed information required to understand what causes disease and death in individual cases due to the many intervening variables and complications (Vieweg et al., 2013). The exception here may be the many cases of CVD linked to the veins and related organ systems that are very likely the result of intravenous drug use with unclean syringes, leading to infections. In this study, especially diseases of the veins were associated with injection use, benzodiazepine use and prescription methadone use, and being referred to methadone maintenance treatment. Since a likely underlying mechanism for this particular type of CVD is infections resulting from injection drug use, the best explanation for the links between methadone and benzodiazepine use is that these factors are indicators of a more chaotic and serious pattern of drug use.

Whether a more direct link exists between prescription use of methadone and onset of CVD is more uncertain. While we did observe statistically independent links between both self-reported methadone prior to treatment and referral for methadone treatment at entry and new onset of CVD, it is also possible that these significant findings are based on unobserved higher drug use severity among patients who were referred to methadone maintenance treatment.

\section{Clinical implications}

The observation that patients referred for methadone maintenance and using drugs intravenously had elevated risk for CVD should lead clinicians and treating physicians to pay extra attention to the cardiovascular health of patients who receive methadone, especially since this group of patients may have difficulty accessing healthcare in the general health system (Robbins et al., 2010).

People working at safe injection rooms, in substitution treatment, and general practitioners who have contact with injection drug users or patients in substitution treatment should be aware of these risks. In terms of patients, doctors need to consider that most patients are well aware that injection drug use is generally hazardous for their health, and education and outreach should be provided primarily for patients who already have or express concern about their cardiovascular health. Adding information about even more risks associated with drug use may even backfire in this population. 


\section{Strengths and limitations}

The main strengths of our study were the use of a large, national sample of patients, complete national registers, and a long period of measurement before and after treatment entry.

Coverage of health and cause of death registers are nearly complete. A small number of private hospitals do perform some heart surgery in Denmark, but the number of patients treated in these hospitals is considered to be so small that it is not of significance for the assessment of the prevalence and incidence of CVD in Denmark (Koch et al., 2011).

Additionally, we were able to control for a range of important indicators of drug use severity and social deprivation. However, the study also had significant limitations. One important limitation is that we do not have sufficient quality data on the Danish Drug Abuse Treatment Register in terms of coverage and quality of the data. Specifically, in the register's data collection form, patients were asked about only last year's substance use, but do not specify if the patient has problem use or any use.

Also, although we could ascertain the coverage of the DATR in relation to patients who came to residential treatment services, people with only brief contacts with treatment for DUD may be missed. Although a high proportion of patients with CVD will end up in treatment, it is possible that especially patients with CVD and DUD may ignore symptoms of CVD longer than people who do not have DUD, and instead cope with pains and discomfort by increasing their use of drugs or alcohol, leading to a possible under-representation of CVD.

A more significant limitation is that we have no data on treatment compliance during treatment. We strongly suspect that monitoring of abstinence during treatment has been highly variable between various areas in Denmark and over time, but we do not have robust data to test the importance of such monitoring in relation to later incidence of CVD.

\section{Conclusions}

Prescription methadone use and injection drug use is associated with new incidence cardiovascular disease among people seeking treatment for drug use disorders. 


\section{Acknowledgements:}

We wish to thank Abdu Kedir Seid for his useful comments on this manuscript.

\section{References}

Danaei, G., Finucane, M. M., Lin, J. K., Singh, G. M., Paciorek, C. J., Cowan, M. J., . . C, Global Burden Metab Risk Factors. (2011). National, regional, and global trends in systolic blood pressure since 1980: systematic analysis of health examination surveys and epidemiological studies with 786 country-years and 5.4 million participants. Lancet, 377(9765), 568-577. doi: Doi 10.1016/S0140-6736(10)62036-3

Danaei, G., Stevens, G., Finucane, M., Lin, J., Singh, G., Paciorek, C., . . . Ezzati, M. (2011). Global, Regional and National Trends in Metabolic Risk Factors of Chronic Diseases: Analysis of Health Surveys and Epidemiologic Studies since 1980. Journal of Epidemiology and Community Health, 65, A52-A52. doi: DOI 10.1136/jech.2011.142976b.49

De Giorgi, A., Fabbian, F., Pala, M., Bonetti, F., Babini, I., Bagnaresi, I., . . Manfredini, R. (2012). Cocaine and acute vascular diseases. Current Drug Abuse Reviews, 5(2), 129-134.

Degenhardt, L., \& Hall, W. (2012). Extent of illicit drug use and dependence, and their contribution to the global burden of disease. Lancet, 379(9810), 55-70.

Desbois, A. C., \& Cacoub, P. (2013). Cannabis-Associated Arterial Disease. Annals of Vascular Surgery. doi: 10.1016/j.avsg.2013.01.002

Farzadfar, F., Finucane, M. M., Danaei, G., Pelizzari, P. M., Cowan, M. J., Paciorek, C. J., . . . C, Global Burden Metab Risk Factors. (2011). National, regional, and global trends in serum total cholesterol since 1980: systematic analysis of health examination surveys and epidemiological studies with 321 country-years and 3.0 million participants. Lancet, 377(9765), 578-586. doi: Doi 10.1016/S0140-6736(10)62038-7

Figueredo, V. M. (2011). Chemical Cardiomyopathies: The Negative Effects of Medications and Nonprescribed Drugs on the Heart. American Journal of Medicine, 124(6), 480-488. doi: DOI 10.1016/j.amjmed.2010.11.031

Fine, J. P., \& Gray, R. J. (1999). A proportional hazards model for the subdistribution of a competing risk. Journal of the American Statistical Association, 94, 496-509.

Haller, B., Schmidt, G., \& Ulm, K. (2013). Applying competing risks regression models: an overview. Lifetime Data Analysis, 19(1), 33-58. doi: 10.1007/s10985-012-9230-8

Kao, D., Bartelson, B. B., Khatri, V., Dart, R., Mehler, P. S., Katz, D., \& Krantz, M. J. (2013). Trends in Reporting Methadone-Associated Cardiac Arrhythmia, 1997-2011 An Analysis of Registry Data. Annals of Internal Medicine, 158(10), 735-+.

Koch, Mette Bjerrum, Davidsen, Michael, \& Juel, Knud. (2011). Hjertekarsygdomme i Danmark [Diseases of the circulatory system in Denmark]. Copenhagen: National Institute on Public Health.

McKenna, M. T., Michaud, C. M., Murray, C. J., \& Marks, J. S. (2005). Assessing the burden of disease in the United States using disability-adjusted life years. American Journal of Preventive Medicine, 28(5), 415-423. 
Nordstrom, D. L., Yokoi-Shelton, M. L., \& Zosel, A. (2013). Using multiple cause-of-death data to improve surveillance of drug-related mortality. J Public Health Manag Pract, 19(5), 402411. doi: 10.1097/PHH.0b013e318271c622

Nyhlén, A., Fridell, M., Hesse, M., \& P., Krantz. (2011). Causes of premature mortality in Swedish drug abusers: a prospective longitudinal study 1970-2006. Journal of Forensic and Legal Medicine, 18(2), 66-72. doi: 10.1016/j.jflm.2011.01.003

O'Brien, Robert M. (2007). A Caution Regarding Rules of Thumb for Variance Inflation Factors. Quality \& Quantity, 41(5), 673-690.

Pedersen, M. U., Hesse, M., \& Bloomfield, K. (2011). Abstinence-orientated residential rehabilitation of opioid users in Denmark: Do changes in national treatment policies affect treatment outcome? Scandinavian Journal of Public Health, 39(6), 582-589. doi: Doi $10.1177 / 1403494811407673$

Pieper, B., Kirsner, R. S., Templin, T. N., \& Birk, T. J. (2007). Injection drug use - An understudied cause of venous disease. Archives of Dermatology, 143(10), 1305-1309. doi: DOI 10.1001/archderm.143.10.1305

Robbins, J. L., Wenger, L., Lorvick, J., Shiboski, C., \& Kral, A. H. (2010). Health and oral health care needs and health care-seeking behavior among homeless injection drug users in San Francisco. J Urban Health, 87(6), 920-930. doi: 10.1007/s11524-010-9498-5

Roy, A. K., McCarthy, C., Kiernan, G., McGorrian, C., Keenan, E., Mahon, N. G., \& Sweeney, B. (2012). Increased incidence of QT interval prolongation in a population receiving lower doses of methadone maintenance therapy. Addiction, 107(6), 1132-1139. doi: DOI 10.1111/j.1360-0443.2011.03767.x

Salmon, A. M., Dwyer, R., Jauncey, M., van Beek, I., Topp, L., \& Maher, L. (2009). Injectingrelated injury and disease among clients of a supervised injecting facility. Drug and Alcohol Dependence, 101(1-2), 132-136. doi: DOI 10.1016/j.drugalcdep.2008.12.002

Vieweg, W. V., Hasnain, M., Howland, R. H., Clausen, T., Koneru, J. N., Kogut, C., . . Pandurangi, A. K. (2013). Methadone, QTc interval prolongation and torsade de pointes: Case reports offer the best understanding of this problem. Ther Adv Psychopharmacol, 3(4), 219-232. doi: $10.1177 / 2045125312469982$ 
Table 1. Descriptive statistics for the cohort $(\mathrm{N}=18,275)$

\begin{tabular}{|c|c|c|c|c|c|c|}
\hline & $\begin{array}{l}\text { History if CVD } \\
(n=828)\end{array}$ & & $\begin{array}{l}\text { No history of CVD } \\
(n=17,447)\end{array}$ & & $\begin{array}{l}\text { Odds ratio } \\
\text { of being } \\
\text { prevalent }\end{array}$ & P-value \\
\hline & $\mathrm{N}$ & $\begin{array}{l}\text { Percentage/standard } \\
\text { deviation }\end{array}$ & $\mathrm{N}$ & $\begin{array}{l}\text { Percentage/standard } \\
\text { deviation }\end{array}$ & & \\
\hline \multicolumn{7}{|c|}{ Drugs used past-year at baseline (non-exclusive) } \\
\hline Methadone, illicit & 104 & $12.56 \%$ & 1,830 & $10.49 \%$ & 1.22 & 0.059 \\
\hline Methadone, prescribed & 330 & $39.86 \%$ & 2,420 & $13.89 \%$ & 4.11 & 0.000 \\
\hline Other opioids & 327 & $39.49 \%$ & 6,188 & $53.47 \%$ & 1.19 & 0.018 \\
\hline Benzodiazepines & 168 & $20.29 \%$ & 3,073 & $17.61 \%$ & 1.19 & 0.049 \\
\hline Cocaine & 117 & $14.13 \%$ & 3,594 & $20.60 \%$ & 0.63 & 0.000 \\
\hline Amphetamine & 83 & $10.02 \%$ & 3,658 & $20.97 \%$ & 0.42 & 0.000 \\
\hline Cannabis & 294 & $35.51 \%$ & 9,334 & $53.50 \%$ & 0.48 & 0.000 \\
\hline Alcohol & 155 & $18.72 \%$ & 4,302 & $24.66 \%$ & 0.70 & 0.000 \\
\hline \multicolumn{7}{|l|}{ Infection risk behaviour } \\
\hline Ever injected & 280 & $33.82 \%$ & 4,484 & $27.99 \%$ & 2.27 & 0.000 \\
\hline Not reported & 383 & $46.26 \%$ & 6,033 & $34.58 \%$ & 2.51 & 0.000 \\
\hline No previous treatment $^{1}$ & 545 & $64.80 \%$ & 7,084 & $40.63 \%$ & 0.37 & 0.000 \\
\hline Referred for methadone treatment & 437 & $52.78 \%$ & 4,206 & $24.11 \%$ & 3.51 & 0.000 \\
\hline Male gender & 575 & $69.44 \%$ & 13,274 & $76.08 \%$ & 0.71 & 0.000 \\
\hline Age in years & 39.34 & 10.02 & 30.62 & 9.51 & 1.08 & 0.000 \\
\hline Working or studying ${ }^{2}$ & 127 & $15.43 \%$ & 5,580 & $34.04 \%$ & 0.35 & 0.000 \\
\hline Immigrant & 56 & $6.76 \%$ & 1,372 & $7.86 \%$ & 0.85 & 0.247 \\
\hline Born to immigrant parents & 9 & $1.09 \%$ & 203 & $1.16 \%$ & 0.92 & 0.813 \\
\hline Criminal history in past year & 513 & $61.96 \%$ & 9,628 & $55.18 \%$ & 1.32 & 0.000 \\
\hline Any mental health care in past year & 163 & $19.69 \%$ & 3,115 & $17.85 \%$ & 1.13 & 0.000 \\
\hline
\end{tabular}

Table 2. Prevalence of cardiovascular disease among patients aged 18-74 and in the general population

\footnotetext{
${ }^{1}$ Reference categories not included.

${ }^{2}$ Individuals with missing data not included (n=177, 5 with CVD, 172 with no CVD).
} 


\begin{tabular}{|c|c|c|c|c|c|c|c|c|}
\hline & Men & & & & Women & & & \\
\hline Age & $\begin{array}{l}\text { No CVD } \\
(\mathrm{N})\end{array}$ & CVD (N) & Percentage & $\begin{array}{l}\text { Population } \\
\text { prevalence } 2009^{3}\end{array}$ & No CVD (N) & CVD (N) & Percentage & $\begin{array}{l}\text { Population } \\
\text { prevalence } 2009^{4}\end{array}$ \\
\hline $18-24$ & 4,236 & 36 & $0.84 \%$ & & 1,481 & 17 & $1.13 \%$ & \\
\hline $25-34$ & 4,836 & 153 & $3.07 \%$ & & 1,284 & 73 & $5.38 \%$ & \\
\hline $35-44$ & 3,024 & 195 & $6.06 \%$ & $1.89 \%$ & 927 & 96 & $9.38 \%$ & $1.71 \%$ \\
\hline $45-54$ & 1,070 & 169 & $13.64 \%$ & $7.79 \%$ & 408 & 52 & $11.30 \%$ & $6.51 \%$ \\
\hline $55-64$ & 107 & 26 & $19.55 \%$ & $17.32 \%$ & 70 & 15 & $17.65 \%$ & $11.94 \%$ \\
\hline $65-74$ & 12 & 6 & $33.33 \%$ & $27.85 \%$ & 9 & 3 & $25.00 \%$ & $18.48 \%$ \\
\hline Total & 13,274 & 575 & $4.22 \%$ & & 4,173 & 253 & $5.77 \%$ & \\
\hline
\end{tabular}

\footnotetext{
${ }^{3}$ (Koch et al., 2011, table 9-2.).

${ }^{4}$ (Koch et al., 2011).
} 
Table 3. Predictors of New Incidence of Cardiovascular Disease (competing risks regression)

$\mathrm{N}=17,262$, Total days at risk: 47,102,864. Incident cases: $\mathrm{n}=1,529$, Dying of unrelated causes: $\mathrm{n}=1,508$, Wald $\chi^{2}(17)=457.53$, $\mathrm{p}<0.0001$

\begin{tabular}{|c|c|c|c|c|}
\hline & Sub-hazard ratio & 95\% CI- & $95 \% \mathrm{CI}+$ & P-value \\
\hline \multicolumn{5}{|l|}{ Drugs $^{5}$} \\
\hline Prescribed methadone & 1.32 & 1.15 & 1.51 & 0.000 \\
\hline Illicit methadone & 1.05 & 0.90 & 1.22 & 0.559 \\
\hline Other opioids & 1.10 & 0.98 & 1.24 & 0.111 \\
\hline Benzodiazepines & 1.21 & 1.06 & 1.38 & 0.005 \\
\hline Cocaine & 0.94 & 0.81 & 1.10 & 0.461 \\
\hline Amphetamine & 0.76 & 0.64 & 0.90 & 0.002 \\
\hline Cannabis & 0.93 & 0.83 & 1.04 & 0.211 \\
\hline Alcohol & 1.00 & 0.88 & 1.15 & 0.984 \\
\hline \multicolumn{5}{|l|}{ Infection risk behaviour } \\
\hline Never injected & Reference & & & \\
\hline Injected & 1.45 & 1.25 & 1.67 & 0.000 \\
\hline Not reported & 1.24 & 1.07 & 1.43 & 0.003 \\
\hline Referred for methadone maintenance & 1.15 & 1.02 & 1.31 & 0.022 \\
\hline \multicolumn{5}{|l|}{ Previous treatment } \\
\hline Yes & Reference & & & \\
\hline No & 0.97 & 0.86 & 1.08 & 0.568 \\
\hline Female & Reference & & & \\
\hline Male & 0.92 & 0.82 & 1.04 & 0.166 \\
\hline Age at intake in years & 1.04 & 1.03 & 1.04 & 0.000 \\
\hline Working or studying & 0.93 & 0.82 & 1.06 & 0.272 \\
\hline Criminal history in past year & 1.15 & 1.03 & 1.29 & 0.015 \\
\hline Mental health services contact in past year & 1.10 & 0.96 & 1.25 & 0.184 \\
\hline
\end{tabular}

\footnotetext{
${ }^{5}$ Drugs dummy coded, in all cases reference category is non-use of same drug.
} 
Table 4. Types of cardiovascular disease in the sample during the observation period excluding all patients prevalent at intake ( $\mathrm{n}=17,262)$

\begin{tabular}{|c|c|c|c|c|}
\hline & $\begin{array}{l}\text { At hospital contact including } \\
\text { outpatient and inpatient } \\
\text { settings }\end{array}$ & & $\begin{array}{l}\text { As Underlying Cause of } \\
\text { Death }\end{array}$ & \\
\hline & $\mathrm{N}$ & Per 10,000 & $\mathrm{~N}$ & Per 10,000 \\
\hline Acute rheumatic fever & 2 & 1 & 0 & 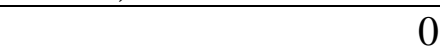 \\
\hline Chronic Rheumatic disease & 4 & 2 & 1 & 1 \\
\hline Hypertension & 83 & 48 & 0 & 0 \\
\hline Ischemic heart disease & 245 & 140 & 26 & 15 \\
\hline Pulmonary heart disease & 87 & 50 & 6 & 3 \\
\hline Pericarditis & 40 & 23 & 0 & 0 \\
\hline Endocarditis & 156 & 89 & 7 & 4 \\
\hline Cardiomyopathy & 29 & 17 & 2 & 1 \\
\hline Conduction disorders & 0 & 0 & 1 & 1 \\
\hline Cardiac arrest & 0 & 0 & 2 & 1 \\
\hline Heart failure & 73 & 42 & 3 & 2 \\
\hline Complications and ill-defined descriptions & 15 & 9 & 8 & 5 \\
\hline Cerebrovascular disease & 253 & 146 & 22 & 13 \\
\hline $\begin{array}{l}\text { Diseases of arteries, arterioles and } \\
\text { capillaries }\end{array}$ & 200 & 116 & 3 & 2 \\
\hline $\begin{array}{l}\text { Diseases of veins, lymphatic vessels and } \\
\text { lymph nodes }\end{array}$ & 1,179 & 692 & 4 & 2 \\
\hline $\begin{array}{l}\text { Other and unspecified disorders of the } \\
\text { circulatory system }\end{array}$ & 92 & 53 & 1 & 1 \\
\hline
\end{tabular}



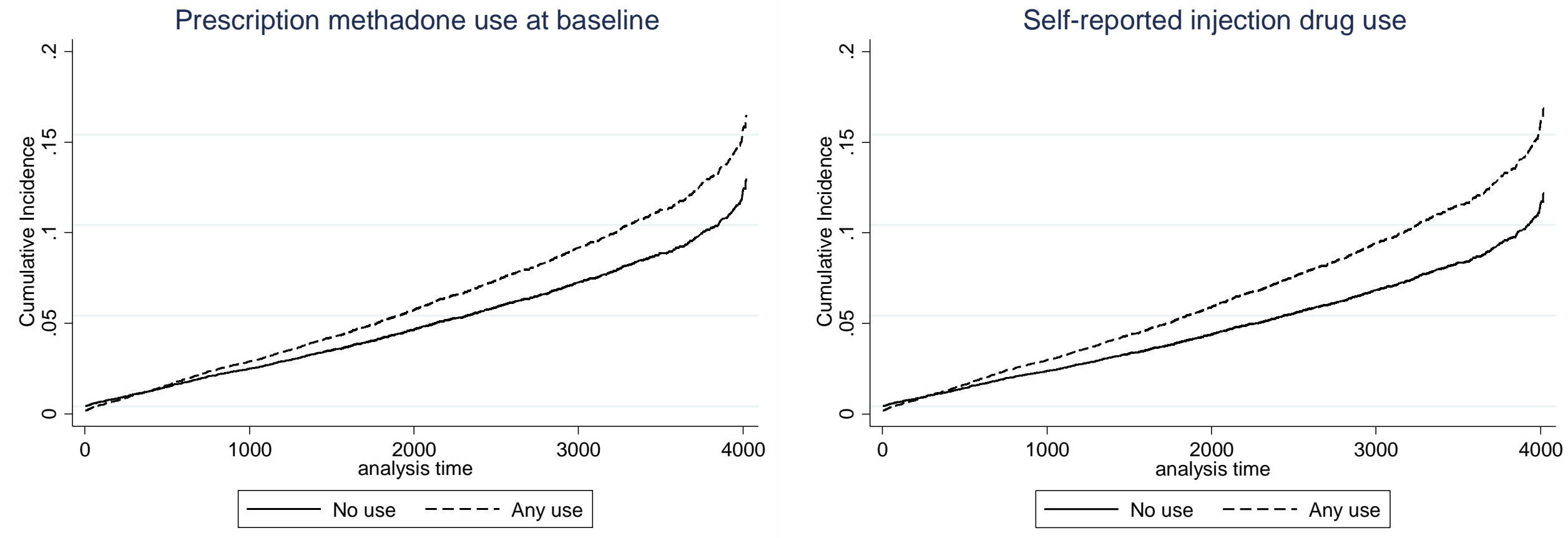

Figure 1. Estimated cumulative incidence function by prescription methadone use (left-hand panel) and injection use (right-hand panel). Analysis time is days in admission to treatment for substance use disorders. 